\title{
Interaktiv und kommunikativ: Sicherer Start in die Freiberuflichkeit
}

Zu seinem ersten Forum Zukunft lädt der Freie Verband Deutscher Zahnärzte (FVDZ) Ende September nach Berlin ein. Interaktiv und kommunikativ wird es bei dem zweitägigen Treffen am 30. September und 1. Oktober um die sichere Zukunftsplanung für junge Zahnärztinnen und Zahnärzte gehen. „Wir wollen den Teilnehmern einerseits ein prall gefülltes Informationspaket mitgeben und gleichzeitig viel Raum dafür lassen, persönliche Fragen im Austausch mit den Referenten und anderen Teilnehmern zu klären“, erläutert die stellvertretende FVDZ-Bundesvorsitzende Dr. Gudrun Kaps-Richter das neue Format. Das Forum Zukunft startet mit einer Führung durch den Bundesrat am Nachmittag des Freitags (30. September). Am Samstag, 1. Oktober, geht es dann ab 9 Uhr um vier Themenschwerpunkte: Rechtsanwältin Melanie Neumann wird im Modul „Beruf und Familie“ über neue Berufsmodelle referieren und Gelegenheit bieten, über wichtige Fragen und Sorgen in Hinblick auf eine Praxisgründung oder das Angestellt-Bleiben zu sprechen. Rechtsanwalt Michael Lennartz widmet sich beim Thema „Angestellt oder Chef" dem Übergang vom Studium in den Beruf und dann in die Freiberuflichkeit. Prozess- und Qualitätsmanager Sascha Kötter referiert zur finanziellen Sicherheit beim Start in die Niederlassung. Im Modul „Erfolgreich kommunizieren“ von Rhetoriktrainer Peter Edwin Brand steht die Kommunikation mit Patienten, Chef und Mitarbeitern im Mittelpunkt. Von den Teilnehmern selbst wird ebenfalls intensive Kommunikation gefragt sein: In Workshops arbeiten sie gemeinsam an den Themen weiter.

Weitere Informationen zum Forum Zukunft oder zur Anreise gibt es bei Frauke Garstka in der FVDZ-Bundesgeschäftsstelle in Bonn unter der Telefonnummer 0228/855732 oder per Mail unter fg@fvdz.de. Anmeldungen sind auch direkt im Internet unter www.fvdz.de/forum-zukunft.html möglich.

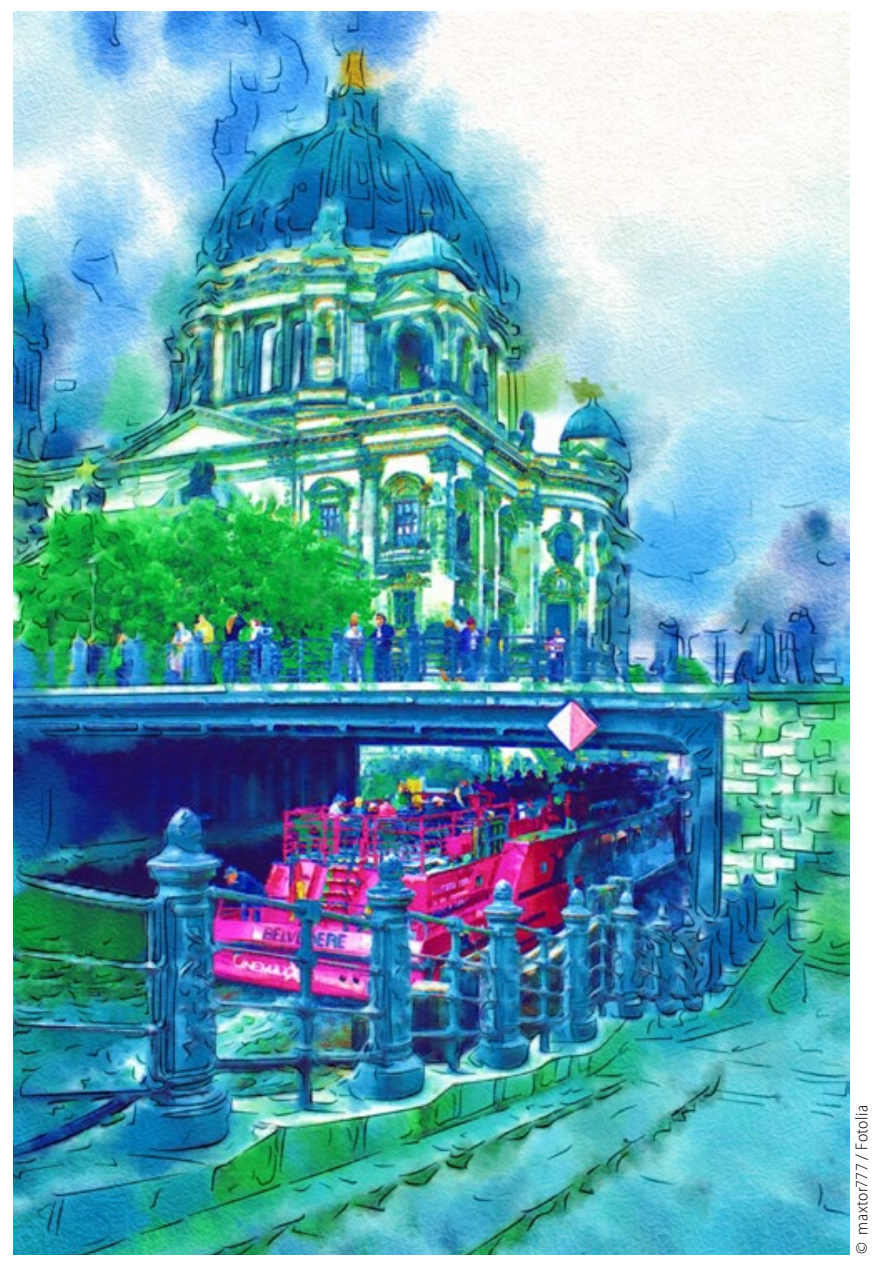

Tag der Zahngesundheit

proDente bietet Zahnärzten und Zahntechnikern Aktionspaket an

Unter dem Motto „Gesund beginnt im Mund - Fakten gegen Mythen" findet am 25. September der Tag der Zahngesundheit statt. Aktuelles Wissen rund um die Mundgesundheit steht dabei im Vordergrund. Die Initiative proDente e.V. greift diesen Gedanken auf und bietet ein umfangreiches Aktionspaket mit Patienteninformationen an. Von A wie Anästhesie bis $Z$ wie Zahnlücke informiert proDente in zahlreichen Broschüren, Magazinen und Flyern über schöne und gesunde Zähne. Interessierte Zahnärzte und Zahntechniker können das kostenfreie Aktionspaket zum Tag der Zahngesundheit für ihre Patienten bestellen. Ein Erklärvideo zum Thema „Professionelle Zahnreinigung (PZR)“ zeigt anschaulich, welchen Beitrag die PZR zur Mundgesundheit leisten kann und wie sie durchgeführt wird. Das Video kann direkt von der proDente Webseite herunterge-

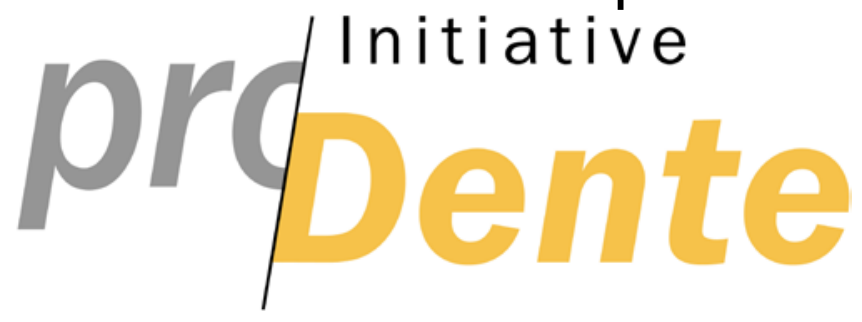

laden und als ein Baustein in der Patientenkommunikation eingesetzt werden. Niedergelassene Zahnärzte und zahntechnische Innungsbetriebe können das kostenfreie Aktionspaket bis zum 25 . September 2016 unter der Telefonnummer 01805/552255 bestellen. Alternativ genügt auch eine Bestellung mit vollständiger und lesbarer Adresse per Fax an 0221/170 99742. 